\title{
Pedagogical Content Knowledge-Guided Lesson Study: Effects on Teacher Competence and Students' Achievement in Chemistry
}

\author{
John Lou S. Lucenario, ${ }^{1}$ Rosanelia T. Yangco, ${ }^{2}$ Amelia E. Punzalan, ${ }^{3}$ and Allen A. Espinosa ${ }^{4}$ \\ ${ }^{1}$ San Jose National High School, 1860 Rodriguez, Rizal, Philippines \\ ${ }^{2}$ Division of Curriculum and Instruction, College of Education, University of the Philippines, 1109 Diliman, Quezon City, Philippines \\ ${ }^{3}$ National Institute for Science and Mathematics Education Development, University of the Philippines, 1109 Diliman, \\ Quezon City, Philippines \\ ${ }^{4}$ Faculty of Science, Technology and Mathematics, College of Teacher Development, Philippine Normal University, \\ 1000 Manila, Philippines \\ Correspondence should be addressed to John Lou S. Lucenario; johnloulucenario@gmail.com
}

Received 14 April 2016; Accepted 13 November 2016

Academic Editor: Karl Kingsley

Copyright @ 2016 John Lou S. Lucenario et al. This is an open access article distributed under the Creative Commons Attribution License, which permits unrestricted use, distribution, and reproduction in any medium, provided the original work is properly cited.

This study aimed to investigate the effectiveness of Pedagogical Content Knowledge-Guided Lesson Study (PCKLS) as an intervention to develop PCK competencies among teachers and consequently enhance student achievement in terms of conceptual understanding and problem-solving skills. Using quasi-experimental design, teacher competencies and student achievement in the PCKLS group and the conventional group were compared. In the PCKLS group, the intervention involved planning the lesson by the research team, teaching the planned lesson while PCK observations were made by the researcher and another teacher from the group, including a feedback meeting, implementing the improvements in the reteach stage of the lesson study cycle by another teacher from the research team, and, finally, revising lesson plans based on the consolidated suggestions for improvement. Analyses of data showed that there was a significant difference in the science teacher competencies of the PCKLS group teacher respondents compared to those of the conventional group. Also, student respondents showed a significant increase on mean scores in terms of conceptual understanding and problem-solving skills. Therefore, it was concluded that PCKLS was an effective method to develop the teachers' PCK competencies and student achievement in terms of conceptual understanding and problem solving. This study recommends that this intervention be used across chemistry topics and in other science classes such as Biology, Earth and Environmental Science, Physics, and Mathematics.

\section{Introduction}

In recent years, policymakers nationwide have begun to focus on how to help teachers cope with the increasingly sophisticated methods for engaging diverse students in mastering challenging subject content and basic skills. In Japan, lesson study has been firmly established as a trend to improve teachers' pedagogical content knowledge. According to Richardson [1], lesson study is a culture of professional development activity that shows teachers the value of working together while sharing with and observing each other while teaching. The University of the Philippines National Institute of Science and Mathematics Education Development (UP
NISMED) has been strongly advocating lesson study. In their intensive research involving public school chemistry teachers, lesson study presents strong evidence of teachers' effectiveness as seen in student achievement [2]. This is consistent with the claim of Darling-Hammond [3] that teacher qualities are important determinants of student achievement. The teaching and learning process among teachers bring along the knowledge components. Hill et al. [4] said that pedagogical content knowledge (PCK) is an essential and critical element in determining a teacher's success in handling the teaching and learning process and further produces effective teaching. PCK has been qualified as deeply personal, highly contextualized, and influenced by teaching interaction 
and experiences [5]. Therefore, the lesson study approach to teaching can be a timely effort to enhance teachers' competence especially in chemistry education since it is highly structured to involve collaborative interaction of teachers and sharing of experiences based on actual teaching.

In science and mathematics education, the overall vision of the Trends in International Mathematics and Science Study (TIMSS) in the improvement of standards among science educators has been the baseline in professional development efforts. In chemistry education, these efforts have been focused on improving teachers' understanding about the current trends in chemistry teaching and learning [6]. In this study, the program for chemistry teacher-leaders was designed to include all the necessary components that comprise the lifelong professional development of science teachers as well as components that are unique to the development of leadership among chemistry teachers. The Philippines in this case, through the joint effort of the Department of Science and Technology (DOST) and the UP NISMED, developed the Framework for Science Teacher Education (FSTE) - a rubric that aims to measure science teachers' competencies for professional development. Thus, lesson study, being a competency-based approach to teaching, is now gaining much attention for science education development to enhance teaching competencies.

This study seeks to investigate the effects of PCK-guided lesson study on chemistry teachers' competence and student achievement in terms of problem-solving skills.

Specifically, the study aims to answer the following research questions:

(1) Do teachers exposed to PCKLS have higher teacher competence than those exposed to conventional teaching preparation approach?

(2) Do students exposed to PCKLS chemistry instruction have significantly higher achievement than those exposed to conventional teaching preparation approach?

\section{Literature Review}

2.1. On Teacher Competence. The 21st century has been a period of change, especially in the field of science education, as it is considered to be the cornerstone of economic development. In this perspective, teachers are considered to play key roles in achieving this goal and are expected to improve their knowledge and skills to enhance their teaching practices [7].

Science education to some extent depends on the degree of professional and pedagogical competence of teachers. Baranović [8] said that there is really a need therefore to redefine teachers' professional development for sustainability. The general components of teacher competencies were presented by Selvi [7] as follows: field, research, curriculum, lifelong learning, social-cultural, emotional, and communication. These aim to bring out systematic and scientific results towards meeting the needs of individuals and society. Shulman [9] studied the characteristics of teachers' knowledge and claimed that professional teachers must possess certain competencies to be called effective. In science teaching, an effective teacher must have high regard for scientific competencies rather than simple contents and topics.

In line with the call to enhance teacher competencies, in 2006, the Philippine Education for All (EFA) Plan 2015, through the Basic Education Sector Reform Agenda (BESRA), provided a framework that defines effective teaching in all aspects of a teacher's professional life and in all phases of teacher development through the National Competency-Based Teacher Standards (NCBTS). Aiming to standardize the science teacher competencies for professional development, the University of the Philippines National Institute for Science and Mathematics Education Development (UP NISMED) and the Department of Science and Technology (DOST) jointly identified the qualities of effective science teachers. Mainly this stems from their confidence of the subject matter, how to teach it (pedagogy), and their attitude. Earlier studies of these institutions, however, were focused on the growing recognition of the need for competent mathematics teachers to alter the practices in the teaching of mathematics and to improve pupils' as well as teachers' performance in mathematics [10]. Thus, to measure and develop these science teachers' competencies the said institutions drafted the Framework for Science Teacher Education (FSTE) which serves to meet the said goal of science education (SEIDOST and UP NISMED, 2011).

2.2. On Pedagogical Content Knowledge (PCK). In the past decades, research on teaching and learning has been focused on teachers' subject area content knowledge and the method of knowledge transfer to students. For some, these researches are acknowledgments of the complexity brought about by the teaching process which aims to contribute to the empowerment of teachers, the enhancement of the teaching status, and the improvement of the pedagogical content knowledge (PCK) of teachers. According to Niess [11], subject matter knowledge is important as it defines and develops the teacher's content of instruction. In the modern method of instruction, technology has become an integral component for learning across subject matter areas-an intersection of technology-based subject matter knowledge with pedagogical content knowledge as it requires thorough understanding of the methods of the integration process. Therefore, it is vital that science and mathematics teachers develop pedagogical content knowledge with the integration of technology-based approaches. In the study conducted by Barak and Dori [12], ICT-supported learning environment could significantly enhance students' ability to traverse chemistry understanding levels and their understanding of chemical concepts, theories, and the structure of molecules. Moreover, a collaborative inquiry using Knowledge Forum (a networked environment for knowledge building) is an effective tool for students with appropriate levels of scaffolding about portfolio assessment (van Aslst \& Chan, 2007).

2.3. On Science Pedagogical Content Knowledge. Science has been considered to be the key towards economic development. Thus, there is a pressing need to develop student knowledge and skills. This is possible through the students and 
teachers' concerted efforts. According Darling-Hammond [3] teacher qualities are important determinants of student achievement. Therefore, there is a need to focus on teacher competence through the development of teachers' PCK. It has been recognized that the foundation of science PCK is thought to be the amalgam of a teacher's pedagogy and understanding of content such that it influences his/her teaching in ways that will best stimulate student learning for understanding [13]. This emphasis on PCK is justified based on the assumption that PCK can make a significant impact on the quality of instruction that the students receive and thus the quality of learning the students experience in the classroom [14, 15]. In support of this idea, Hill et al. [4] said that pedagogical content knowledge (PCK) is an essential and critical element in determining a teacher's success in handling the teaching and learning process that further produces effective teaching.

\subsection{On Chemistry Pedagogical Content Knowledge. Chem-} istry, as a specific discipline under science, has complexities that must be addressed by the teacher as a product of experiences through time. Thus, there is a need to specifically develop one's specific PCK in this discipline. To do this, Großebrahm \& Rumann [16] claim that prospective chemistry teachers have to be familiar with national curricula in chemistry education, and they have to know about chemistryspecific objectives. Curriculum is so dynamic that it changes regularly. It is critical for teachers to be sensitive and prepared for the reality that students will always need knowledge from previous years, a factor that is less significant in biology and yet critical in chemistry. Teachers should not underestimate how certain factors could influence student attitudes towards chemistry. Another aspect that could affect student interest in learning chemistry is the duration or limits of chemistry concepts. Knowledge that is imparted at school is temporary and generates dissatisfaction. Knowing strategies to handle this situation has to be a part of reflective chemistry PCK. Thus, a teacher must have a strong foundation in pedagogical knowledge as to understand learners' psychology and the principles behind their behavior.

2.5. On Lesson Study. In recent years, there have been several studies focusing on effectiveness of teachers as it is recognized to determine student achievement. Hence, teacher professional development has been a constant priority of the education sector. It is believed that effectiveness of teachers can be achieved by the grounding professional development in actual classroom practice [17]. To address this educational goal, it has been decades since Japan pioneered such effort through their distinct professional development program called lesson study. This program has been described as a way of teacher development and a product of collaboration based on class observation and critiquing. In the original context, Lewis et al. [18] explained lesson study terms and key features into Kenkyuu jugyou meaning research lesson or study lesson which refers to the actual classroom lessons that teachers planned together, observed, and discussed and Jugyou kenkyuu refers to the process of instructional improvement of which the research lesson is the central element. Lewis and Tsuchida [19] explained that in Japan lesson study, it is generally shared with the following procedure: design and plan a research lesson together, teach it with teachers from the group, observing and recording the lesson, and then discuss the lesson with the teachers in the lesson study group and make revisions of the lesson; then another teacher from the group teaches the lesson to his/her class and the cycle repeats. The main feature, however, is to enhance teachers' professional development through a cyclical process that comprises curriculum study and goals formulation, planning, conducting research, and reflecting on the research lessons [20]. This leads to developing the capacity of teachers to enhance teaching and increase knowledge of the lesson delivery through peer learning - and environment that is necessary to improve PCK [21].

In the Philippines, lesson study has been initiated by UP NISMED. Dela Cruz et al. [2] stated that lesson study is a practical, economical, and effective school-based method for continuous professional development of teachers done in a collegial atmosphere. In the study, it was strongly suggested that teachers during the lesson study process must be aware of their responsibility to teach students correctly and the group should include a subject expert or a teacher who is a major in the subject.

While most researches on lesson study reported positive development of teachers' competence, its sustainability is dependent upon building leaders generating a shared vision with professional development as a priority. This calls for the move to develop a leader of professional development to an active partner and to build administrators who are willing to allow teachers to take leadership roles throughout the lesson study process. It is stressed that these leaders must become learners who are willing to engage in the reciprocity of teaching and learning during the lesson study process sending a clear message that ongoing professional development is a nonnegotiable requirement for all. This brings about the idea that in professional development activities, teachers participate in the job with their colleagues, actively engaged in discourse, and plan and reflect on lessons that are contentfocused which lead to positive change in teacher knowledge and practice and an improvement in student learning.

2.6. Conceptual Framework. This study, as shown in Figure 1, will focus on the effects of PCK-guided lesson study on the competencies of chemistry teachers and achievement of their students.

The primary independent variable is the teaching approach: PCK-guided lesson study (PCKLS) for the experimental group and the Conventional Teaching Approach for the control group. In this study, PCKLS group employed the modified lesson study guided by the Chemistry Teachers' PCK-guided Lesson Study Observation Checklist (CTPLSOC) which was used by the expert observer and the researcher.

The PCKLS process includes the following: designing and planning a research lesson together, teaching it with teachers 


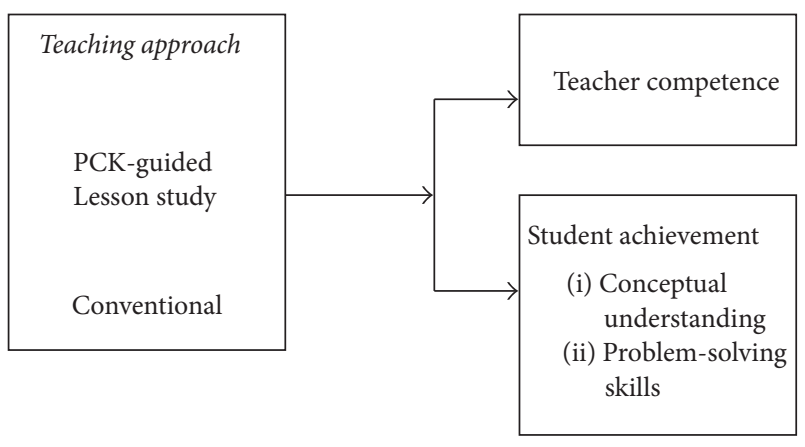

FIgURE 1: Conceptual framework.

from the group, observing and recording the lesson, discussing the lesson with the teachers in the lesson study group, and making revisions of the lesson based on the Chemistry Teachers' PCK-guided Lesson Study Observation Checklist (CTPLSOC); then another teacher from the group teaches the same lesson to his/her class with similar competencies adapting the points for improvement given to the previous teacher and the cycle repeats.

On the other hand, the conventional group used the typical prescribed Basic Education Curriculum (BEC) teaching approach. In this approach, the teacher prepared the lesson plan and other instructional preparations independently.

The two dependent variables were teacher competencies and student achievement. These variables were measured using Assessment on Chemistry Teachers' Pedagogical Content Knowledge (ACTPCK) and Solution Concentration Problems (SCP), respectively.

2.7. Research Hypotheses. The research hypotheses of this study were:

(1) Teachers exposed to PCKLS have higher teacher competence than those exposed to conventional teaching preparation approach.

(2) Students exposed to PCKLS chemistry instruction have significantly higher achievement than those exposed to conventional teaching preparation approach.

\section{Methods}

3.1. Research Design. This study used the quasi-experimental research design. Two different regular high schools in Region IVA were purposively chosen by evaluating their Mean Percentage Score (MPS) in the Division Achievement Test (DAT) for the last three (3) consecutive years. The chosen schools were of equal performance based on the said criterion. Each of these schools was randomly assigned either as experimental or control group.

As illustrated in Figure 2, the experimental group teacher respondents used the PCK-guided lesson study as an intervention in their chemistry classes which focused on concentration of solution subtopics, while the control group used the conventional teaching method. To measure the effects of the intervention, teachers' before, during, and after PCK were evaluated using the Assessment on Chemistry Teachers' Pedagogical Content Knowledge (ACTPCK) and The Framework for Science Teacher Education (FSTE). The researcher observed the teacher respondents during the evaluation using the ACTPCK while video records on actual classroom setup were used by an expert. The teacher respondents rated themselves using the FSTE.

To determine the effects of PCKLS on student achievement in terms of conceptual understanding and problemsolving skills, the students' pre- and posttest mean scores were assessed using the Concentration of Solutions Concept Test (CSCT) and the Solution Concentration Problems (SCP), respectively. Moreover, evidence-based qualitative analyses using the Lesson Study Student Observation Form (LSSOF) were employed to evaluate the observation data and evidence during intervention.

Figure 2 shows the research design used in the study.

3.2. The Sample. The data were taken from four chemistry teacher respondents and their respective students from two different regular high schools in Region IVA. The experimental group used the Pedagogical Content KnowledgeGuided Lesson Study (PCKLS) as the teachers' intervention and their respective students while the control group used the conventional teaching. This study was conducted during the second grading period of the school year 2012-2013.

3.3. The Instruments. In this study, the researcher used the following instruments.

3.3.1. Assessment on Chemistry Teachers' Pedagogical Content Knowledge (ACTPCK). This instrument aims to measure the teachers' pedagogical content knowledge (PCK) focusing on four domains as observed in actual lesson study class, namely, Subject Matter Knowledge (SMK), Instructional Objective and Context (IOC), Knowledge of Student Understanding (KSU), and Instructional Representation and Strategies (IRS). This was used by the observer as pretest and posttest to assess the chemistry teachers' PCK. This was adopted and modified from Jang et al. [13]. The reliability of this instrument has a Cronbach alpha value of 0.965 , indicating that the questionnaire had a good internal consistency. Moreover, based on the factor loadings, the items in each category were deleted that had low item-scale correlations from the reliability section and had factor loadings less than 0.40 , indicating its good validity.

\subsubsection{Chemistry Teachers' PCK-Guided Lesson Study Obser-} vation Checklist (CTPLSOC). This checklist aims to elicit chemistry teachers' pedagogical content knowledge (PCK) focusing on four domains as observed in the actual lesson study class. The data obtained were used as guide for the improvement of the teacher competence for the succeeding lesson study. This checklist was used by the observers during the actual lesson studies and served as a guide to develop the chemistry teachers' PCK. This was adopted and modified from Jang et al. [13]. 


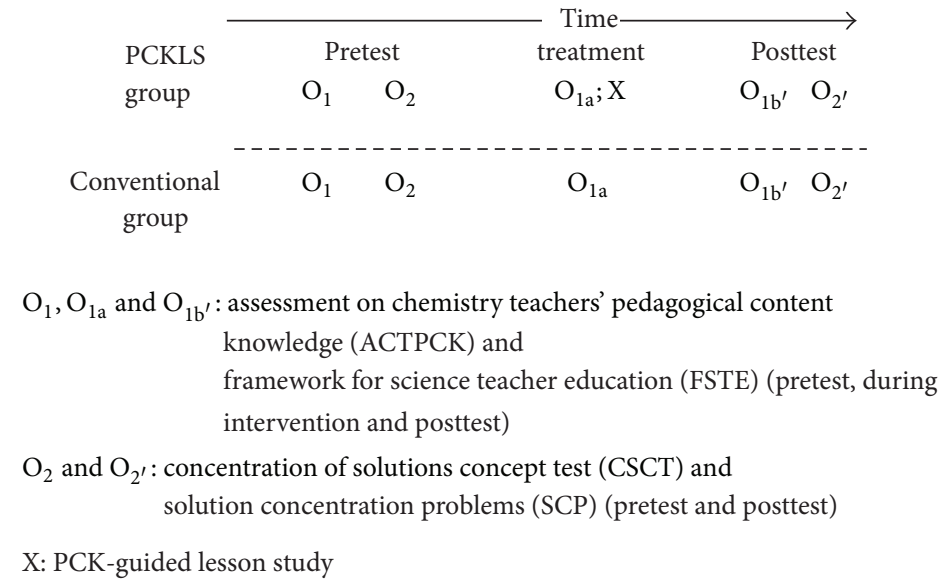

FIGURE 2: Research design.

3.3.3. Framework for Science Teacher Education (FSTE). This is a self-assessment tool constructed by the Department of Science and Technology (DOST) and University of the Philippines National Institute for Science and Mathematics Education, aiming to measure science teachers' professional knowledge, practices, and attributes.

3.3.4. Lesson Study Student Observation Form (LSSOF). This is an observation form that aims to record actual observations and evidences during class. It includes anything students say or do which demonstrates their thinking about the topic and concepts, like comments and/or questions in group and whole class discussions, engagement with materials, or written work, including drawings and representations. All data obtained using this form was analyzed qualitatively. This was adopted and modified from Weiland et al. [22].

3.3.5. Concentration of Solutions Concept Test (CSCT). This is a researcher-made multiple-choice test that aims to measure the conceptual understanding of the students regarding concentration of solutions subtopic in secondary chemistry. Topics included basic questions on percentage by volume, percentage by mass, and Molarity, which were designed at the level of application, analysis, and synthesis. This instrument was validated followed by pilot testing to fourth year students. Reliability analysis yielded acceptable internal consistency value (Cronbach's alpha) of .81. This means that the items as well as the options in the test are well represented within the cognitive abilities of the students.

3.3.6. Solution Concentration Problems (SCP). This refers to the test on concentration of solution which was constructed by the researcher. Topics in the instrument included problems on percentage by volume, percentage by mass, and Molarity. This test determined the achievement level of the students in terms of problem-solving skills. Rubrics were provided to standardize scoring. This was also validated and subjected to reliability analysis (Cronbach's alpha) which gave a high internal consistency value of .83 .
3.4. Data Collection Procedure. The data were taken from two different regular public high schools in Rodriguez, Rizal. The two schools were chosen initially by evaluating their Mean Percentage Score (MPS) in the recent three (3) consecutive years of the Division Achievement Test (DAT). The data for the said preevaluation were taken from the DepEd Division Office of Rizal two months before the data was properly gathered. The DAT MPS's of the chosen schools were found to have no significant difference based on the said criterion (53.09 and 52.45).

\subsection{Treatment}

3.5.1. The PCK-Guided Lesson Study Group. The PCK-guided lesson study (PCKLS) group was the experimental group of the study. In this group, the classes were taught using the PCK-guided lesson study on topics covering concentrations of solutions. Course guide with learning competencies were provided which was followed by the teacher respondents. Lesson delivery was mostly student-centered as practiced by the lesson study approach. Pre-and posttests of teacher respondents and students were compared. In particular, the series of events during the intervention was elaborated in the previous discussions.

3.5.2. The Conventional Group. The conventional group was the control group. The teacher respondents taught the class using the prescribed Basic Education Curriculum (BEC) teaching procedure. However, the same competencies for general high school chemistry were used. It is distinct in this group that the lesson planning and other lesson preparations were done by the teacher respondents independently. Furthermore, topics and the duration of the lessons were similar to the PCK-guided lesson study group. Similar instruments were used to determine the PCK of the teacher respondents and student participants.

3.6. Data Analysis Procedure. Prior to data gathering, the researcher ensured that the conditions for the participating 
schools were followed as follows: no significant difference in terms of students performance as indicated in their DAT MPS and at least three years of teaching experience of the teacher respondents. This is very important to ensure that there is no significant difference between the groups prior to the intervention. Furthermore, this comparability of the two groups was crucial in determining the effects of lesson study on both the PCK of the teacher respondents and the student achievement in terms of conceptual understanding and problem-solving skills.

After the intervention, the data were tabulated and analyzed using parametric and gap-closing measure, inductively. The Hake factor/g factor/normalized gain were used to determine the difference in teacher respondents mean scores between PCKLS and control group. This gap-closing measure is associated with Hake [23] having the following formula:

$$
\mathbf{g}=\frac{\text { Posttest Score }- \text { Pretest Score }}{\text { Maximum Score }- \text { Pretest Score }}
$$

On the other hand, the Student $t$-test, for paired samples, was used to determine if there was a significant difference in the pre- and posttest mean scores of the PCKGLS students in the CSCT and the SCP. On the other hand, the Student $t$ test of independent samples was used to determine if there were significant differences in the CSCT and SCP mean scores of the PCKGLS group and the conventional group. Levels of significance were all set at 0.05 .

\section{Results and Discussion}

4.1. Research Schools. The study was conducted in two public high schools in the Municipality of Rodriguez (formerly Montalban), Province of Rizal. The two schools were randomly assigned as either the PCKLS group or the conventional group, respectively. The PCKLS school has five main buildings and is situated in the densely populated Barangay of San Jose, near the municipal public market and commercial establishments. It was founded in 2002 with a current population of 2,600 students and 81 teachers. On the other hand, the conventional school has five main buildings and a science laboratory room and is situated within a village owned by Iglesia ni Cristo (INC) at Barangay San Jose. It is around 13 years old and caters to almost all students from the said subdivision. Presently, it has 2,344 students and 45 teachers.

4.2. Teacher Respondents' Profile. The teacher respondents' profile includes the basic qualifications of the teacher respondents which were discussed separately as experimental and control respondents. The need to study and analyze the teachers' profile is in support of the recent study of Campo [24] who concluded that chemistry teaching background greatly influences the teacher's PCK. Hypothetical names of teachers were preferably used in this study for confidentiality purposes. All teachers are Filipinos and their mother tongue or language is also Filipino.

\subsection{The PCKLS Group Teachers}

Teacher Dona. She is a chemistry teacher in the PCKLS school for three years, a graduate of Bachelor in Secondary Education major in Physical Science, and a holder of the Licensure Examination for Teachers (LET). She had already attended various seminars related to chemistry.

Teacher Cery. She is the science department chairman and chemistry teacher in the PCKLS school for eight years. She graduated with a Bachelor's degree in Secondary Education, major in chemistry. She is also a holder of the Licensure Examination for Teachers (LET), with earned master's units in the same field, and also she attended various sciencerelated seminars.

\subsection{The Conventional Group Teachers}

Teacher Ana. She is a chemistry teacher in the conventional school. She graduated with a Bachelor's degree in Secondary Education, major in General Science; she is a Professional Board Examination for Teachers (PBET) passer and presently teaching chemistry and a science department chairman for ten years. She has been teaching chemistry for 39 years $(30$ years from private institutions and nine years from the said public high school). She earned master's units in the same field and also attended various science-related seminars.

Teacher Tina. She is a chemistry/biology teacher in the same school. She graduated with a Bachelor's degree in Secondary Education, major in chemistry; she is a holder of the Licensure Examination for Teachers (LET) and has been a teacher for 12 years (nine years in private institutions and three years in the said school). She also had exposures to seminars in the field of science education.

\subsection{Student Respondents' Profile}

PCKLS Group Student Respondents. The PCKLS classes are mostly dominated by girls with ages ranging from 13 to 20 years old. Most of the student population comes from Barangay San Jose, Rodriguez, Rizal, and the neighboring barangays. Many of their parents hold blue-collar jobs like construction laborers, farmers, drivers, vendors, and OFW's and a few are unemployed parents. Some of the parents are office employees. Majority of the students are Roman Catholics, a few Muslims, and Protestants.

Conventional Group Student Respondents. These groups of student respondents are evenly distributed in terms of their gender with ages ranging from 13 to 16 years old. Most of the students come from the Tagumpay Village, San Jose, Rodriguez, Rizal, in which their religion is dominated by Iglesia ni Cristo. Most of their parents are private and public employees while others are construction workers, farmers, drivers, vendors, and some Overseas Filipino Workers (OFW's). 


\subsection{Teacher Competence}

4.6.1. Initial Comparability of Teacher Competence. Prior to the Pedagogical Content Knowledge-Guided Lesson Study, teacher respondents' competencies were determined using the Assessment on Chemistry Teachers' Pedagogical Content Knowledge (ACTPCK) and the Framework for Science Teacher Education (FSTE). The ACTPCK primarily determined the teachers' PCK while the FSTE measured the teacher respondents' professional knowledge, practices, and attributes. The teacher respondents were assessed by the researcher through classroom observation together with an expert through the recorded videos of an actual classroom setting. Using the same instrument and following the validated rubrics for evaluation, the ratings of both the researcher and the expert yielded satisfactory result with a kappa value of 0.464 . This signifies that the criteria for evaluation that were presented in the rubrics can be utilized.

4.6.2. Evidence of Teacher Competence during Intervention. The Pedagogical Content Knowledge-Guided Lesson Study was implemented after the assessment of the initial PCK of the PCKLS teacher respondents using the ACTPCK and the FSTE. Initially, the researcher, together with the teacher respondents, discussed the competencies needed to be improved based from the pretest results of the ACTPCK and the FSTE. During the study, the PCK during the PCKLS classes were also assessed by the researcher and an expert following similar procedure of the pre-PCK assessment. Moreover, constant professional sharing on actual classroom procedures was also done to ensure that all areas of improvement are observable in the next lesson study cycle. The discussion was guided by the Chemistry Teachers' PCK-guided Lesson Study Observation Checklist (CTPLSOC) which covered all observations and the results of the teacher and students' interviews. It is, however, significant to note here that the lesson cycle of the PCKLS is a teach-reteach process by two teacher respondents. This cycle involves three basic steps: (1) teaching implementation of a teacher respondent using the PCKLS; (2) professional sharing by the researcher and both teacher respondents; (3) reteach and implementation of all the areas of improvement of another teacher respondent. This procedure complies with the objective of this study which is to improve the teachers' PCK competencies in their next lesson study, improve the previous lesson study during the reteach phase, and consequently improve student achievement in terms of conceptual understanding and problem solving. The lesson studies focused on different ways to express the concentration of solution, namely, percentage by mass, percentage by volume, percentage by mass/volume, and Molarity concepts.

4.6.3. Effects of PCKLS on Teacher Competence. After the intervention, the teacher respondents' competencies and performance were again measured using ACTPCK and FSTE, respectively. This was done to determine if the PCKLS had a positive impact on the competencies and scientific teaching performance of the teacher respondents.
Results show that after the intervention, teacher respondents in the PCKLS groups showed higher normalized gain score of 0.87 than the control group having 0.16 . Thus, the PCKLS group improved their teacher competence compared to the control group after the intervention. This positive increase in the competence of the PCKLS teacher respondents is attributed to PCKLS as a new intervention in chemistry teaching. As an innovative teaching approach, it provided an avenue for the teacher respondents in connecting their teaching experiences with reflections to promote new insights into the teaching process, thus contributing to their process of reframing and revising their own practice [25]. During the intervention, the teacher respondents were guided by the researcher to conduct group reflection which was one of the factors that contributed to the significant increase in their PCK. In the group reflection, the teacher respondents' analysis of the nature of the learners and the learning environment stimulated their thinking about specific instructional strategies in this area.

On the other hand, using the FSTE, the PCKLS teacher respondents rated their post-PCKLS performance. This was done to let them assess their own performance as science educators after the intervention.

Results show that after the intervention, using the FSTE, the teacher respondents in the PCKLS groups showed higher normalized gain score of 0.43 than the control group having 0.10 . Thus the PCKLS group improved their teacher competence compared to the control group after the intervention. The PCKLS teacher respondents improved their teaching competence after the intervention along with the results of the ACTPCK; the significant increase in the mean scores of the teacher respondents shows the positive impact of the intervention in chemistry classes.

The result of the PCKLS is aligned with the study of Chew et al., [26] wherein 24 lesson study groups composed of preservice secondary teachers for teaching mathematics with Geometer's Sketchpad (GSP) significantly improved after lesson study. Moreover, Lim [27] reported that $98 \%$ of the preservice teachers agreed that the lesson study process has improved their content knowledge and skills in planning a lesson and 95\% reported they had gained new teaching ideas from the program. While $90 \%$ of the preservice teachers complained that the program took up a lot of their time, they agreed that it was still a worthwhile endeavor. It can be deduced that these observations could be attributed to lesson study which has made them more reflective about their own teaching $(90.4 \%)$ and more confident to teach the topic $(85.6 \%)$ and has strengthened peer relationships (89.1\%). It is therefore worth the effort that PCKLS be implemented since positive effects can be gained such as promoting peer collaboration, gaining new teaching ideas, and improving teaching skills.

4.7. Student Achievement. Results show that PCKLS had a positive result in the development of the problem-solving skills of the students. This study, however, intended to develop teacher competence in teaching concentration of solutions in chemistry classes in order to develop students' conceptual 
understanding and problem-solving skills. In the study of Scantlebury [28], teachers who completed a degree primarily to improve their content knowledge significantly improved their teaching skills as seen in the significant increase of the achievement levels of their students. It is, however, recommended in this paper that aside from the development of the teachers' content knowledge, other aspects such as an understanding of sociocultural teaching and learning context, the curriculum, the students' diversity, students' learning needs, and the chemistry teachers' implementation of various strategies to engage students in the learning process should also be considered to fully develop students' achievement in chemistry.

In most of the previous researches, it has been discovered that pedagogical content knowledge (PCK) is an essential and critical element in determining a teacher's success in handling the teaching and learning processes in the classroom. It is important therefore that teacher education and professional development should be aligned with students' perspective of learning [29]. This study supports this claim that in order to be successful, teacher development programs should be aligned with the development of the various interventions in order to address pitfalls in students' understanding of basic chemistry concepts. Adedoyin [30] claimed in his study that in order to be an effective school mathematics teacher, one needs a strong background in mathematics and a thorough understanding of pedagogy. According to Ball et al. [31], PCK enables a teacher to predict complications that may be faced by students and thus prepare themselves with methods, explanations including useful and suitable analogies or representation, and symbols in expressing certain lesson topics. Eggen and Kauchak [32] emphasized that where pedagogical content knowledge is lacking, "teachers commonly paraphrase information in learners' textbooks or provide abstract explanations that are not meaningful to their students." Ehindero [33] confirmed that teacher's teaching is influenced by the level of the acquired pedagogical content knowledge of subject matter. It is therefore clear that the teachers' mastery of the subject matter and its good use in the process of teaching and learning will always indicate the depth of teachers' knowledge of the subject matter.

\section{Conclusion and Recommendations}

5.1. Conclusions. After the results were presented and analyzed qualitatively and quantitatively, the researchers claim that the PCK-guided lesson study was an effective method to improve teacher's competence and student achievement in terms of conceptual understanding and problem-solving skills in chemistry.

(1) The teacher respondents exposed to PCKLS have higher teacher competence than those exposed to conventional teaching preparation approach.

(2) The student respondents exposed to PCKLS chemistry instruction have significantly higher achievement than those exposed to conventional teaching preparation approach.
5.2. Recommendations. The researchers strongly recommend the following:

(1) The chemistry teachers can conduct PCKLS on specific topics like stoichiometry, gas laws, the mole concept, chemical reactions, and others since these are the least mastered topics.

(2) Administrators can initiate sustainable professional development programs like PCKLS. In this approach, the teachers are initially required to meet with other teachers to plan and improve lessons which eventually become a culture of professional development.

(3) The Teacher Education Institutes (TEIs) and training institutes can use the findings of this study as bases for creating trainings, seminars and educational publications aiming to develop teachers' competence.

(4) Curriculum developers can use the findings of this study as bases for framing the science education curriculum specifically in chemistry.

(5) Textbook and educational material writers can use the learning materials and teaching strategies used in the study as bases to develop their authored materials.

(6) Future science education researchers can also utilize the instruments adapted and used in this study to further investigate the PCK of other teachers and measure student achievement. However, for the inferential statistics to be employed as statistical treatment, the researcher should increase the sample size.

(7) Finally, the Philippine government through the Department of Education should adopt this proven approach to develop teacher competencies which would consequently improve student achievement. This would also help minimize the teacher-centered method in teaching and through the professional sharing in the lesson study cycles, teachers are given chances to reflect and share ideas and expertise with colleague for professional development. However, to guarantee its effectiveness, perennial problems must be solved first, like large class size, inadequate facilities, and overloading of teachers. Also, it is a strong recommendation of the researcher that to maximize its potential the team must be of unconditional and consistent dedication throughout the process in which time is an essential precursor. Hence, the intervention must be done consistently to sustain its effectiveness and eventually create a culture of professional development and consequently of quality education.

\section{Competing Interests}

The authors declare that they have no competing interests.

\section{Acknowledgments}

In memory of a great mentor and good friend Dr. Amelia E. Punzalan (January 28, 1952-March 21, 2015). 


\section{References}

[1] J. Richardson, "Lesson study: teachers learn how to improve instruction," Tools for Schools, February-March 2004, http:// www.nsdc.org/library/publications/tools/tools2-04rich.cfm.

[2] A. Dela Cruz, A. Punzalan, and M. Magno, "Lesson study as professional development model [Presentation Script]," http:// www.slideshare.net/upnismedmultimedia/lesson-study-researchupnismed-revised-625.

[3] L. Darling-Hammond, "Assessing teacher education: the usefulness of multiple measures for assessing program outcomes," Journal of Teacher Education, vol. 57, no. 3, pp. 300-314, 2006.

[4] H. C. Hill, S. G. Schilling, and D. L. Ball, "Developing measures of teachers' mathematics knowledge for teaching," The Elementary School Journal, vol. 105, no. 1, pp. 11-30, 2004.

[5] E. M. Van Dijk and U. Kattmann, "A research model for the study of science teachers' PCK and improving teacher education," Teaching and Teacher Education, vol. 23, no. 6, pp. 885897, 2007.

[6] A. Hofstein and V. N. Lunetta, "The laboratory in science education: foundations for the twenty-first century," Science Education, vol. 88, no. 1, pp. 28-54, 2004.

[7] K. Selvi, “Teachers' Competencies," International Journal of Philosophy of Culture and Axiology, vol. 7, no. 1, pp. 167-175, 2010.

[8] B. Baranović, Nacionalni Kurikulum za Obvezno Obrazovanje u Hrvatskoj: Različite Perspektive, Institut za Društvena Istraživanja u Zagrebu, Zagreb, Croatia, 2006.

[9] L. S. Shulman, "Knowledge and teaching: foundations of the new reform," Harvard Educational Review, vol. 57, no. 1, pp. 123, 1987.

[10] T. Bambico, "Influence of teachers' personal variables to teachers' mathematics achievement and instructional skills: a study on the effectiveness of in-service training in the Philippines," Journal of International Development and Cooperation, vol. 8, no. 1, pp. 161-178, 2001.

[11] M. L. Niess, "Preparing teachers to teach science and mathematics with technology: developing a technology pedagogical content knowledge," Teaching and Teacher Education, vol. 21, no. 5, pp. 509-523, 2005.

[12] M. Barak and Y. J. Dori, "Enhancing undergraduate students' chemistry understanding through project-based learning in an IT environment," Science Education, vol. 89, no. 1, pp. 117-139, 2005.

[13] S. J. Jang, S. Y. Guan, and H. F. Hsieh, "Developing an instrument for assessing college students' perceptions of teachers' pedagogical content knowledge," Procedia Social and Behavioral Sciences, vol. 1, pp. 596-606, 2009.

[14] P. L. Grossman, The Making of a Teacher: Teacher Knowledge and Teacher Education, Teachers College Press, New York, NY, USA, 1990.

[15] S. Park and J. S. Oliver, "Revisiting the conceptualisation of Pedagogical Content Knowledge (PCK): PCK as a conceptual tool to understand teachers as professionals," Research in Science Education, vol. 38, no. 3, pp. 261-284, 2008.

[16] N. Großebrahm and S. Rumann, Identifying Elements of PCK in Chemistry Teacher Education, University of Duisburg-Essen, Faculty Chemistry Education, Duisburg, Germany.

[17] J. F. K. Lee, "A Hong Kong case of lesson study-benefits and concerns," Teaching and Teacher Education, vol. 24, no. 5, pp. 1115-1124, 2008.
[18] C. Lewis, R. Perry, and A. Murata, "How should research contribute to instructional improvement? The case of lesson study," Educational Researcher, vol. 35, no. 3, pp. 3-14, 2006.

[19] C. C. Lewis and I. Tsuchida, "A lesson is like a swiftly flowing river: how research lessons improve Japanese education," American Educator, vol. 22, no. 4, pp. 12-17 \& 50-52, 1998.

[20] Y.-R. Juang, T.-C. Liu, and T.-W. Chan, "Computer-supported teacher development of pedagogical content knowledge through developing school-based curriculum," Educational Technology and Society, vol. 11, no. 2, pp. 149-170, 2008.

[21] C. Lewis, R. Perry, and A. Murata, "Lesson study and teachers knowledge development: Collaborative critique of a research model and methods," Report in Annual Meeting of the American Educational Research Association ERIC ED47812, American Educational Research Association, Chicago, Ill, USA, April 2003.

[22] I. Weiland, V. L. Akerson, M. P. Rogers, and K. Pongsanon, "Lesson study as a tool for engaging preservice teachers in reflective practice," in Proceedings of the National Association for Research in Science Teaching, Philadelphia, Pa, USA, 2010.

[23] R. R. Hake, "Interactive-engagement versus traditional methods: a six-thousand-student survey of mechanics test data for introductory physics courses," American Journal of Physics, vol. 66, no. 1, pp. 64-74, 1998.

[24] P. C. Campo, Pedagogical content knowledge development in high school chemistry instruction [M.S. thesis], College of Education, University of the Philippines Diliman, Quezon City, Philippines, 2012.

[25] L. A. Bryan and S. K. Abell, "Development of professional knowledge in learning to teach elementary science," Journal of Research in Science Teaching, vol. 36, no. 2, pp. 121-139, 1999.

[26] C. M. Chew, C. S. Lim, T. Y. Wun, and H. L. Lim, "Effect of lesson study on pre-service secondary teachers' technological pedagogical content knowledge," in Proceedings of the Seminar Kebangsaan Majlis Dekan Pendidikan IPTA, Universiti Teknologi Malaysia, Johor, Malaysia, 2012.

[27] C. S. Lim, "Promoting peer collaboration among pre-service mathematics teachers through lesson study process," in Proceedings of the Proceedings of 12th IOSTE Symposium: Science and Technology in the Service of Mankin, S. Yoong, M. Ismail, A. N. M. Zin et al., Eds., pp. 590-593, School of Educational Studies, Universiti Sains Malaysia, Penang, Malaysia, August 2006.

[28] K. Scantlebury, "Impact of chemistry teachers knowledge and practices on student achievement," AIP Conference Proceedings, vol. 46, no. 1064, 2008.

[29] S. Loucks-Horsley, P. W. Hewson, N. Love, and K. E. Stiles, Designing Professional Development for Teachers of Science and Mathematics, Corwin Press, Thousands Oaks, Calif, USA, 1998.

[30] O. O. Adedoyin, “The impact of teachers' in-depth pedagogical mathematical content knowledge on academic performance: as perceived by Botswana junior secondary schools pupils," European Journal of Educational Studies, vol. 3, no. 2, 2011.

[31] D. L. Ball, S. T. Lubienski, and D. S. Mewborn, "Research on teaching mathematics: the unsolved problem of teachers' mathematical knowledge," in Handbook of Research on Teaching, V. Richardson, Ed., pp. 433-456, Macmillian, New York, NY, USA, 4th edition, 2001.

[32] P. Eggen and D. Kauchak, Educational Psychology: Windows on Classrooms, Prentice Hall, Upper Saddle River, NJ, USA, 2001.

[33] O. J. Ehindero, "A discriminary function analysis of study strategies, logical reasoning ability and achievement across major teacher undergraduate curricula," Research in Education, vol. 44, pp. 1-7, 1990. 


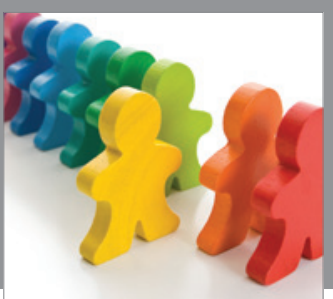

Autism

Research and Treatment
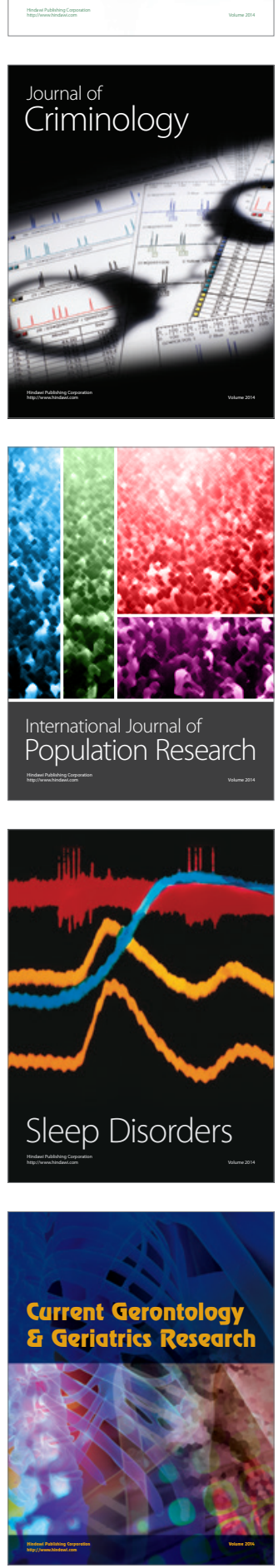

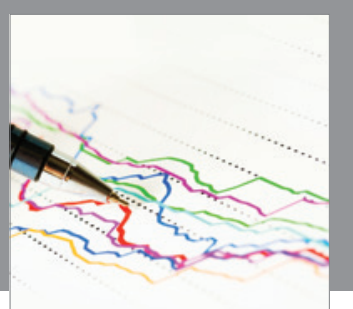

Economics

Research International
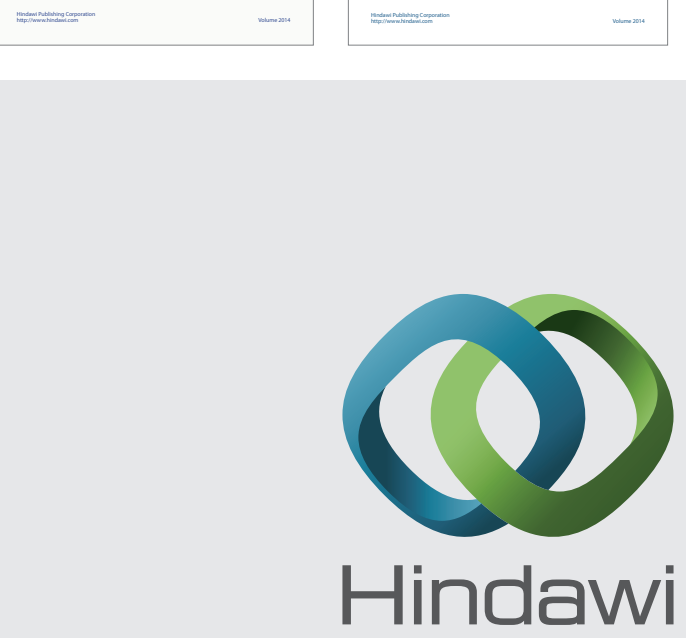

Submit your manuscripts at

http://www.hindawi.com
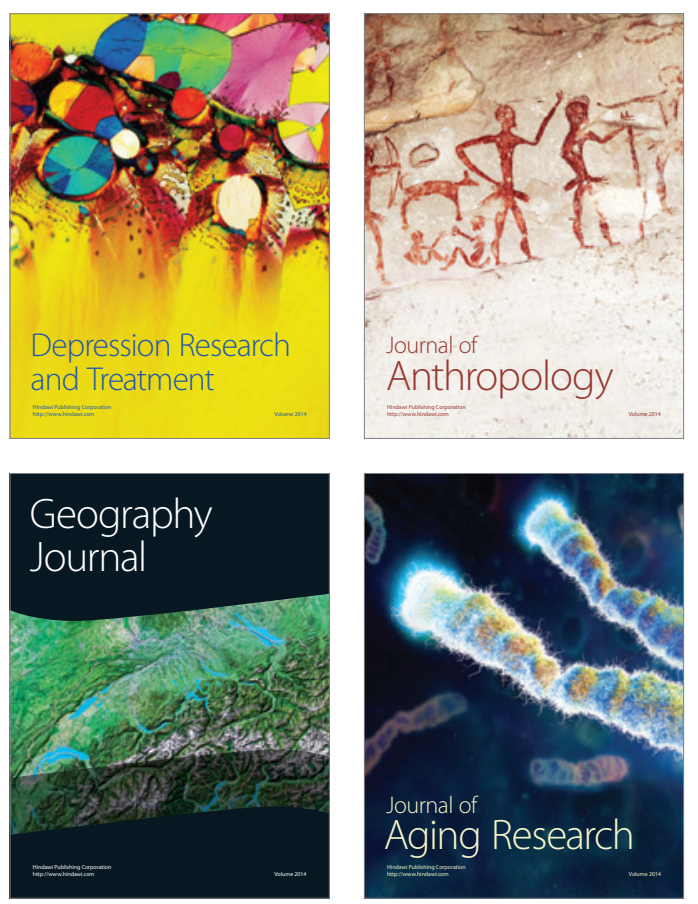
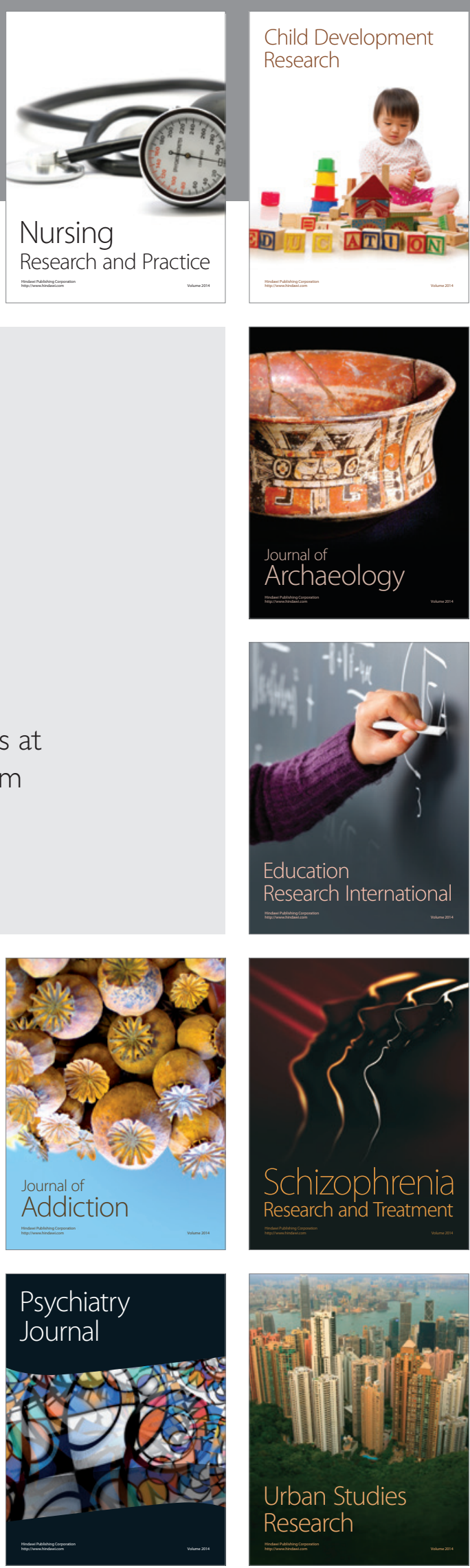